\title{
Impedance Issue of Corrugated Beam Pipe from CDF
}

\author{
King-Yuen $\mathrm{Ng}$ \\ Fermi National Accelerator Laboratory \\ P.O. Box 500, Batavia, Illinois 60510
}

June 1993 


\section{Disclaimer}

This report was prepared as an account of work sponsored by an agency of the United States Government. Neither the United States Government nor any agency thereof, nor any of their employees, makes any warranty, express or implied, or assumes any legal liability or responsibility for the accuracy, completeness, or usefulness of any information, apparatus, product, or process disclosed, or represents that its use would not infringe privately owned rights. Reference herein to any specific commercial product, process, or service by trade name, trademark, manufacturer, or otherwise, does not necessarily constitute or imply its endorsement, recommendation, or favoring by the United States Government or any agency thereof. The views and opinions of authors expressed herein do not necessarily state or reflect those of the United States Government or any agency thereof. 


\title{
IMPEDANCE ISSUE OF CORRUGATED BEAM PIPE FROM CDF
}

\author{
King-Yuen Ng
}

\section{INTRODUCTION}

The CDF collaboration proposed to instal a new corrugated beam pipe at the Tevatron interaction area in order to better monitor the interaction vertex. This note discuss the impedance implication of such a pipe. The drawings of the corrugated pipe are shown in Figs. 1 to 3.

\section{CRUDE ESTIMATION}

This beam pipe has a radius of $b=2$ in and of length 128 in only. It therefore will neither influence in any way the resistive-wall impedance of the whole vacuum chamber, nor will it change the space-charge impedance. As a result, the only features that we need to consider are the roughly $N=222$ corrugations or convolutions, which have a depth of $d-b=0.546 \mathrm{~cm}$ and a width of $g=0.183 \mathrm{~cm}$. Because these convolutions are separated from each other by $1.463 \mathrm{~cm}$, it is not a bad idea to assume that they do not talk to each other. At low frequencies, the longitudinal impedance per unit harmonic is given by

$$
\frac{Z_{\|}}{n}=j \alpha \beta Z_{0} \ln \frac{d}{b},
$$

where $\beta c$ is the velocity of the beam particles, $Z_{0}=377 \Omega$ is the free-space impedance, and $\alpha$ is the fraction of the ring with the corrugations; therefore

$$
\alpha=\frac{N g}{2 \pi R}
$$

where $R=1 \mathrm{~km}$ is the ring radius. Putting in the numbers, we get

$$
\frac{Z_{\|}}{n}=j 0.0047 \Omega,
$$

which should be correct when $n \ll \alpha^{-1}$, or $\ll 0.74 \mathrm{GHz}$. For higher frequencies, we will meet with resonances inside the convolutions. An estimation is that the depth 
of the convolution $d-b=0.546 \mathrm{~cm}$ will sustain a quarter wavelength. Therefore, the lowest resonant frequency is $f \sim c / 4(d-b)=14 \mathrm{GHz}$. Since this is well above cutoff, we expect the resonance to be quite wide.

\section{TBCI}

TBCI was run for a portion of the beam pipe containing 10 convolutions. The longitudinal impedance is shown in Figs. 4 and 5 . We do see a resonance at $\sim 10 \mathrm{GHz}$. For a total of 222 convolutions, we have at low frequencies $Z_{\|} / n=j 0.0045 \Omega$ (at least up to $5 \mathrm{GHz}$ ). The lowest resonance has a width of $\sim 6 \mathrm{GHz}$. The maximum shunt impedance is $\sim 11 \mathrm{k} \Omega$ if the contribution of all convolutions adds constructively; however, this corresponds to a $Z / n$ of $0.05 \Omega$ only.

The transverse impedance from TBCI is shown in Figs. 6 and 7. At low frequencies, $Z_{\perp}=j 12.9 \mathrm{k} \Omega / \mathrm{m}$ for all the convolutions of the beam pipe. The first resonance is again at roughly $10 \mathrm{GHz}$ with a width of $\sim 6 \mathrm{GHz}$. The total maximum shunt impedance is $104 \mathrm{~K} \Omega / \mathrm{m}$ if all convolutions add constructively.

\section{CONCLUSION}

The longitudinal and transverse impedances of the corrugated beam pipe turn out to be quite small $\left(Z_{\|} / n \ll 1 \Omega\right.$ and $\left.Z_{\perp} \ll 1 \mathrm{M} \Omega / \mathrm{m}\right)$ both at low frequencies and at the peak of a resonance. As a result, the installation of this pipe will not lead to any instability of the beam. 


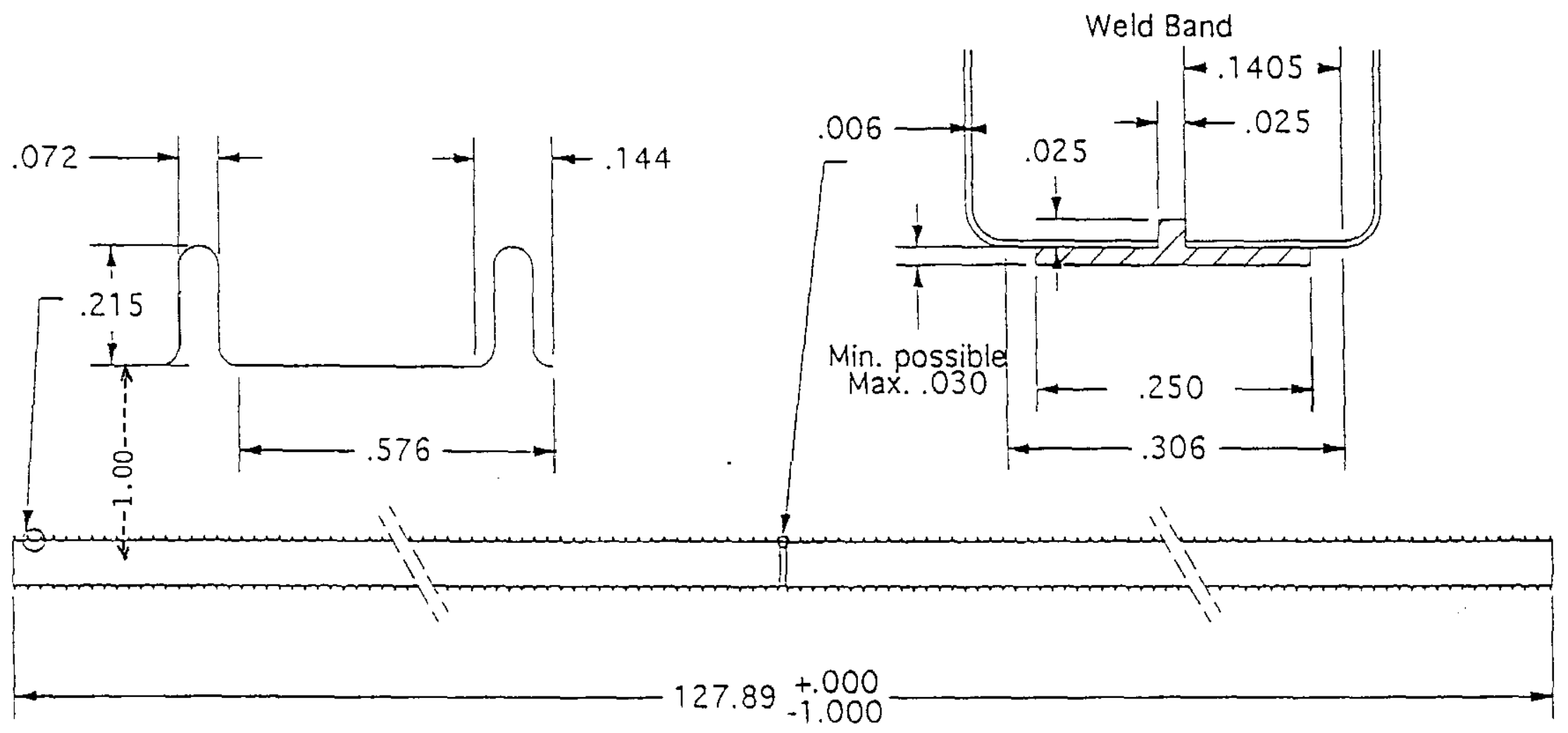

Bellows:

Material: Stainless Steel $\sigma=0.135 \times 10^{7}(\Omega \mathrm{m})^{-1}$

O.D. $=2.43$

I.D. $=2.0$

Pitch of one convolution $=0.144$

Pitch of skipping 3 between each conv. $=0.576$

Wall $=0.006$

\# of Sections $=2$

End connections accomplished by weld bands made

as small and thin as possible, max. thick. $=0.016$

Mass Spec. checked to leak rate of $<1.0 \mathrm{E}-9 \mathrm{cc} / \mathrm{sec}$

Must be able to withstand pressure internally and externally of up to twice atmospheric.

All dimensions in inches.

Figure 1

\begin{tabular}{|c|c|c|c|}
\hline ORAWN & JEFF MUSUR & \multicolumn{2}{|l|}{$9 / 3 / 92$} \\
\hline $\begin{array}{l}\text { AppoveO } \\
\text { or }\end{array}$ & & \multicolumn{2}{|l|}{ Date } \\
\hline 5 & \multicolumn{3}{|c|}{$\begin{array}{l}\text { FERMI NATIONAL ACOELERATOR LABORATORY } \\
\text { UNTEO STATES OEPARTMENT OF ENERGY }\end{array}$} \\
\hline \multicolumn{4}{|c|}{ BELLOWS TRANS SPOOL DESIGN } \\
\hline $\begin{array}{l}\text { SeCLE } \\
\text { NONE }\end{array}$ & $\begin{array}{l}\text { Oonawowic } \\
\text { no. }\end{array}$ & & AEV \\
\hline
\end{tabular}




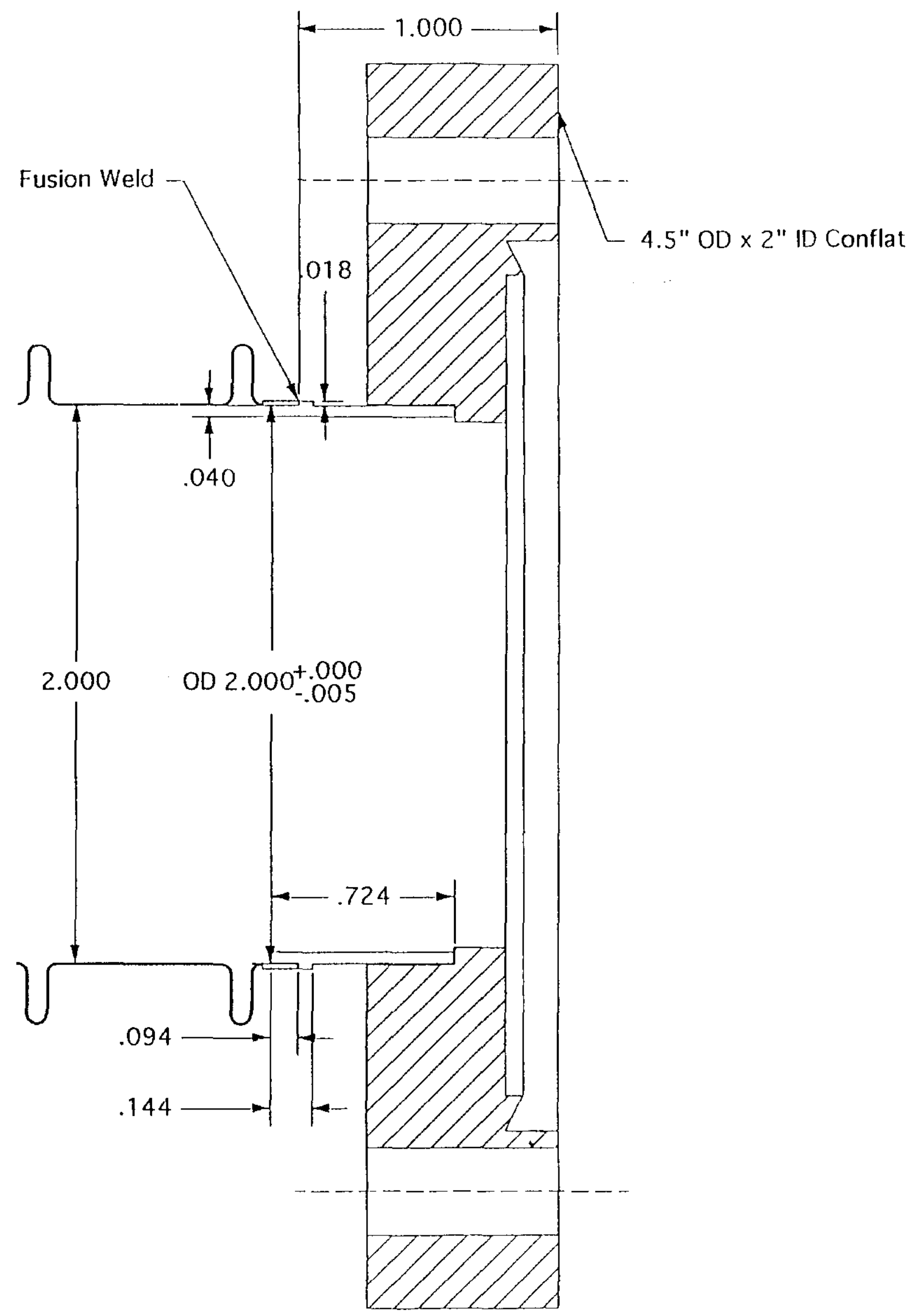

Figure 2 


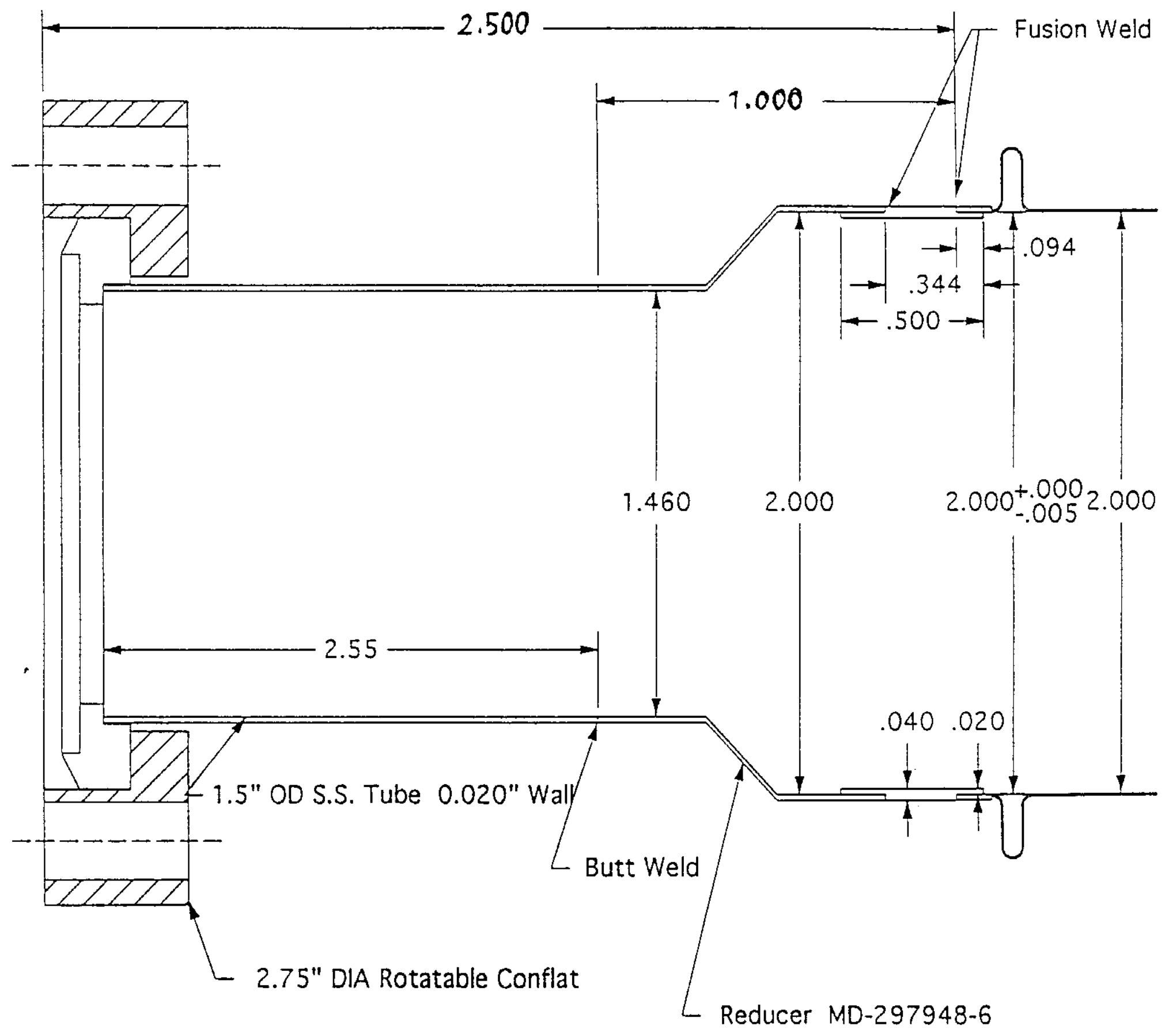

Figure 3 


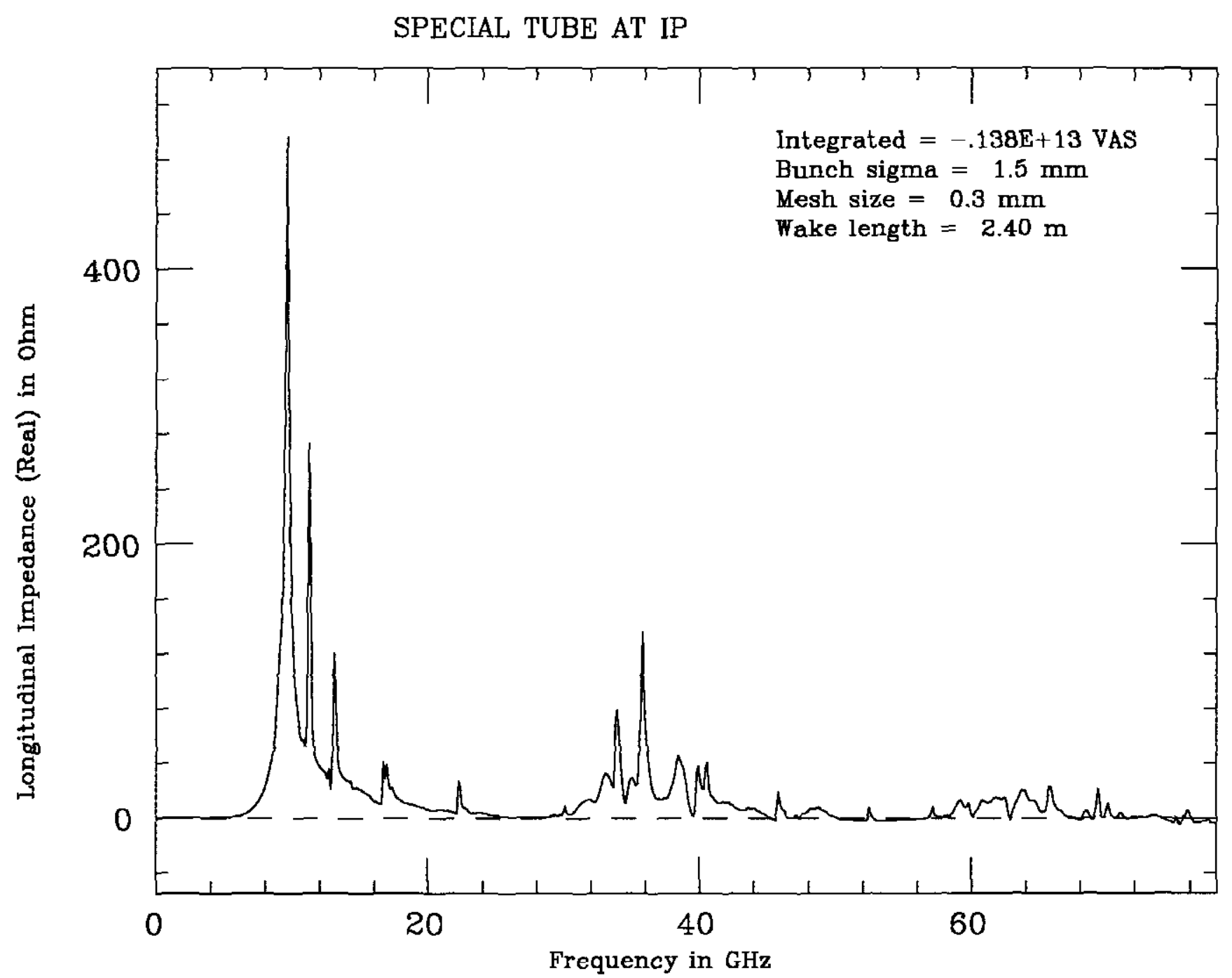

Figure 4 


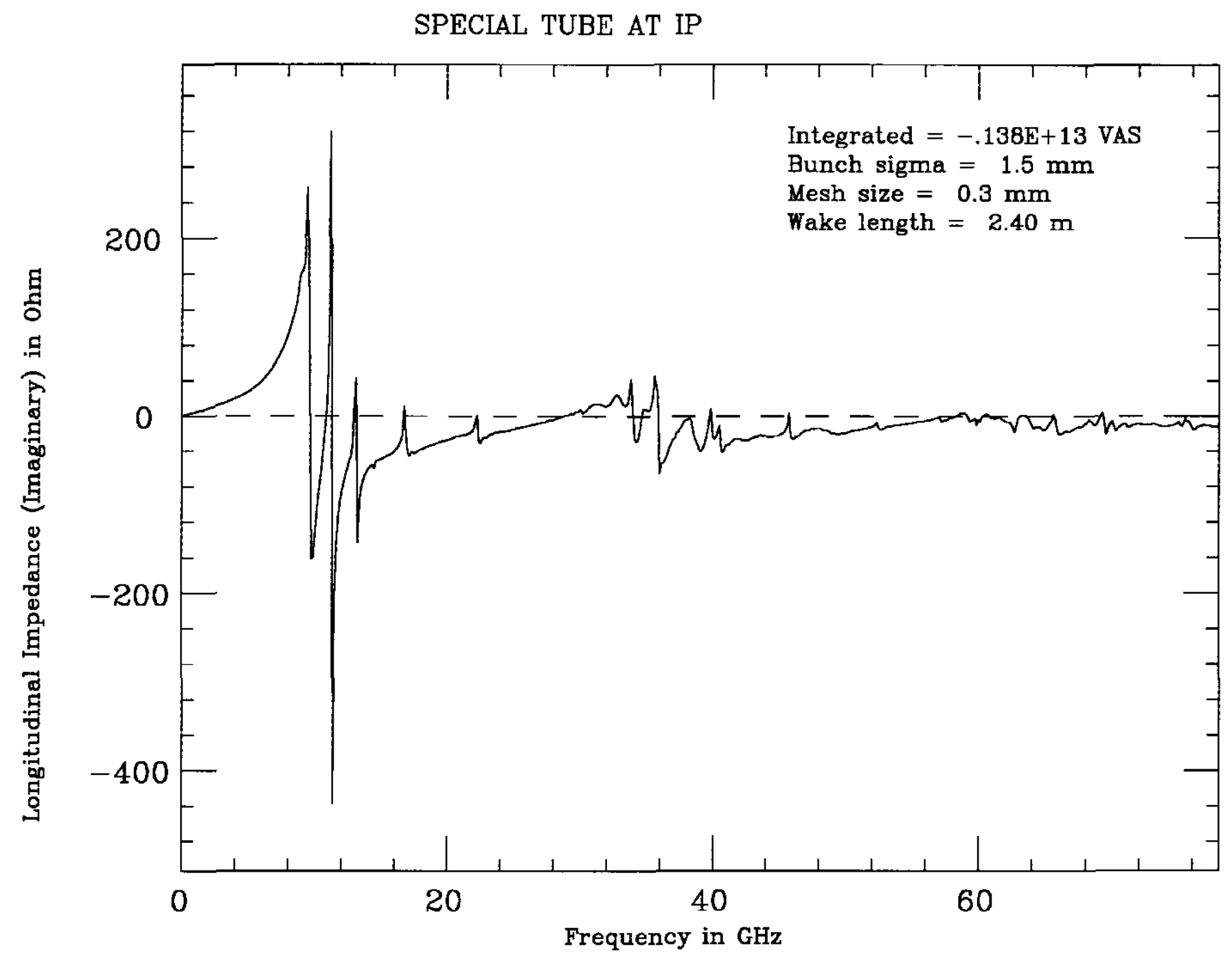

Figure 5 


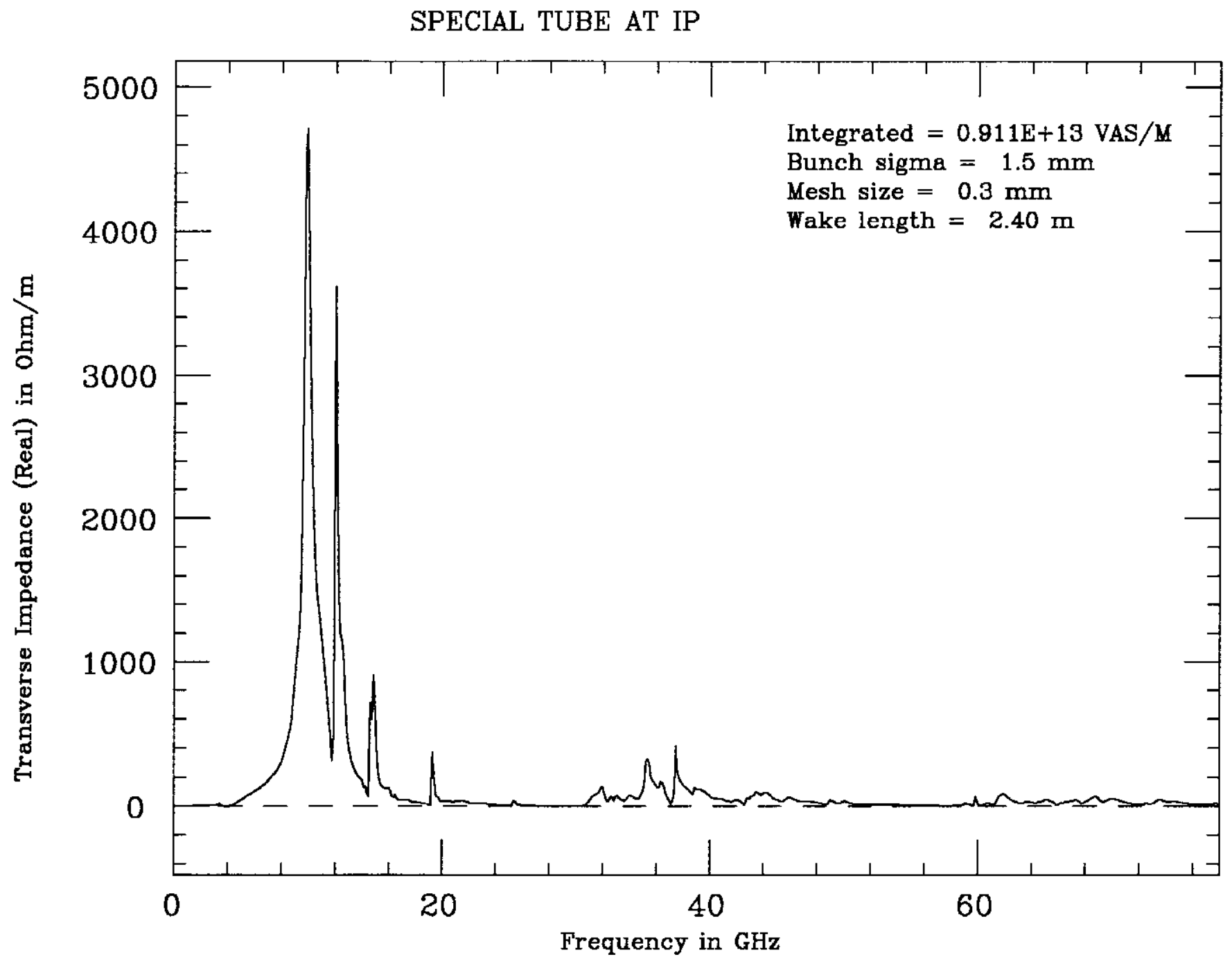

Figure 6 


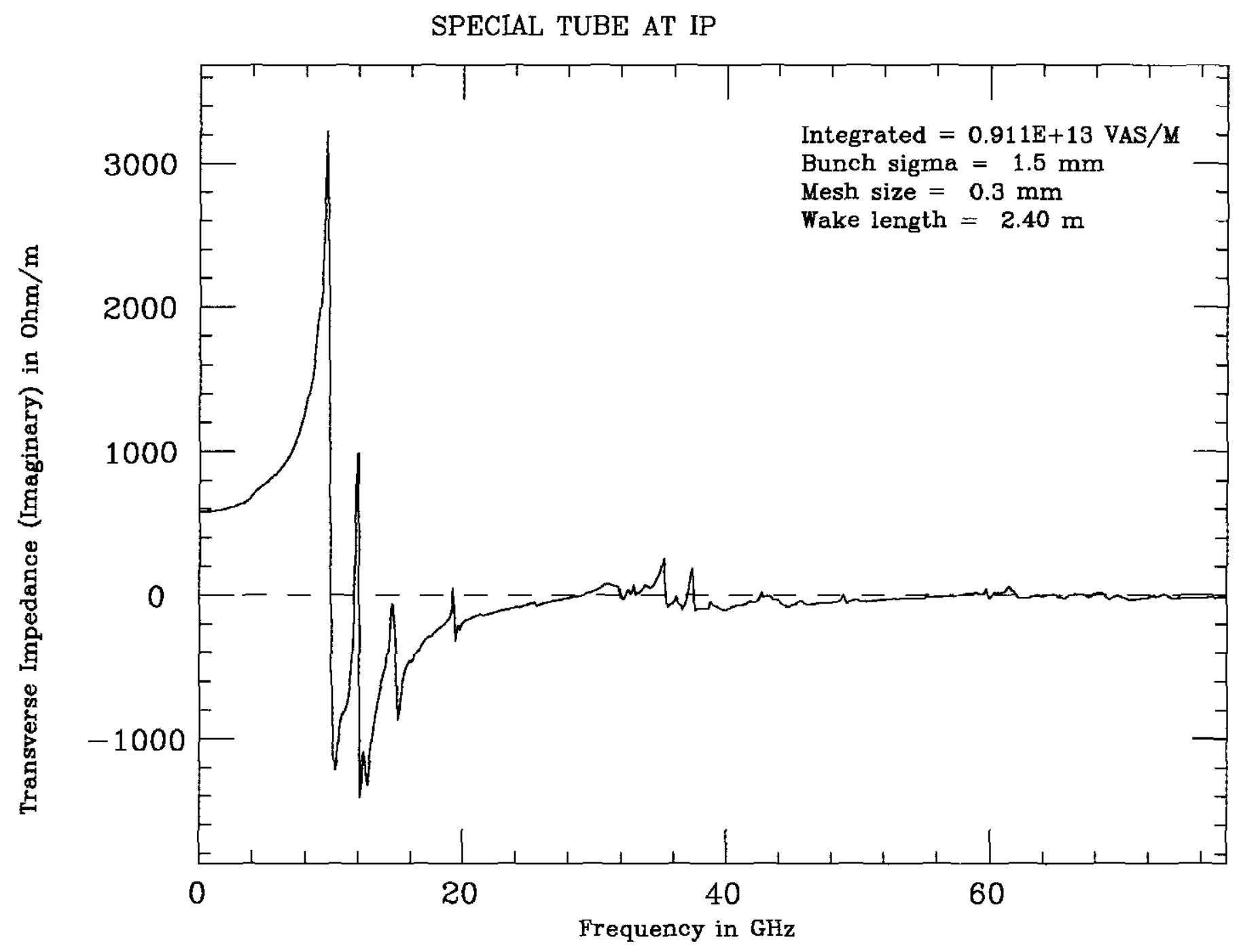

Figure 7 